\title{
O habitus em Bourdieu e a teoria da justificação de Boltanski e Thévenot
}

Guilherme Paiva de Carvalho Martins*

Marcela Carvalho Martins Amaral*

Resumo: $\mathrm{O}$ artigo trata das teorias da ação social na sociologia. Para tanto, destaca a noção de habitus em Bourdieu e os modos de justificação de Boltanski e Thévenot. Com o conceito de habitus, Bourdieu pretende superar a dicotomia entre indivíduo e sociedade. Ao enfatizar a importância das estruturas sociais no direcionamento da ação, Bourdieu se aproxima do estruturalismo. Em Boltanski e Thévenot, os modos como as pessoas justificam as suas práticas e as operações críticas são essenciais para a investigação da ação social. Para categorizer os regimes de ação mediante a análise dos modos de justificação, Boltanski e Thévenot utilizam o aporte teórico da filosofia política.

Palavras-chave: ação social, habitus, justificação

Abstract: This article treats the theories of the social action in the sociology. In order to do so, it was emphasized the notion of habitus in Bourdieu and Boltanski's and Thévenot's justifications ways. With the habitus concept, Bourdieu intends to overcome the dichotomy between individual and society. By emphasizing the importance of the social structures in the direction of the action, Bourdieu approaches the structuralism. In Boltanski and Thévenot, the ways which the persons justify their practices and the critical operations are essentials for the investigation of the social action. For categorizing the regimes of action by analyzing the ways of justification, Boltanski and Thévenot made use of theoretical support from the politic philosophy.

Keywords: social action, habitus, justification.

*Doutor em sociologia e professor do Programa de Pós-Graduação em Letras da UERN. E-mail: guilhermemartins@uern.br.

* Doutoranda do Programa de Pós-Graduação em Sociologia da Universidade de Brasília (UnB).

Latitude, vol. 3 , n², pp. 94-106, 2009.

DOI: https://doi.org/10.28998/2179-5428.20090206 
Guilherme Paiva de Carvalho Martins

Marcela Carvalho Martins Amaral

\section{Introdução}

“[...] que tipo de relação devemos estabelecer, de um lado, entre os motivos explícitos [...] aos quais as pessoas associam suas ações, e, de outro, os esquemas interiorizados e amplamente inconscientes, aos quais o observador exterior confere um poder determinante na geração das condutas"?

Luc Boltanski

Desde o desenvolvimento da sociologia como ciência, a análise da ação social é vista como uma questão basilar para a demarcação do campo de estudos propriamente sociológico e a formulação de metodologias, técnicas de pesquisa e formas de abordagem dos fenômenos sociais. Tratada por autores da sociologia clássica, como Weber e Durkheim, a ação social se constitui como uma questão crucial para as ciências sociais.

Na sociologia contemporânea, a ação social foi discutida por autores como Parsons, Bourdieu, Boltanski, Thévenot, dentre outros. Uma das principais problemáticas discutidas pelas teorias da ação social está relacionada com a dicotomia entre indivíduo e sociedade, subjetividade e objetividade, estruturas estruturadas e estruturas estruturantes. Propomos, no presente artigo, uma discussão de concepções importantes para a abordagem da ação social, destacando as contribuições de Bourdieu, Boltanski e Thévenot.

Para tratar da ação social, Bourdieu formulou o conceito de habitus, caracterizando-o como as disposições adquiridas pelos indivíduos a partir de estruturas. Ao conceber as disposições como preferências incorporadas pelos agentes sociais de estruturas estruturantes, a abordagem de Bourdieu, apesar de propor a superação da relação entre indivíduo e sociedade, parece permanecer vinculada a uma concepção determinista e, por conseguinte, estruturalista da ação social.

Por sua vez, na análise da ação social, a teoria dos regimes de ação e das operações críticas de Boltanski e Thévenot (1991) enfatiza o modo como atores e atrizes sociais justificam as suas práticas em situações cotidianas. Boltanski e Thévenot (1991) propuseram uma teoria dos regimes de ação e das operações críticas, privilegiando a capacidade crítica e reflexiva dos indivíduos.

Com o propósito de discutir a perspectiva dos autores supracitados, o artigo foi subdividido em três partes. Na primeira, retomamos o conceito de habitus em Bourdieu, bem como a formação de disposições e as preferências nos indivíduos são tratadas na segunda parte do artigo. Seguindo os referenciais teóricos de Bourdieu, apontamos, na segunda parte, os limites do conceito de habitus para a compreensão da ação social. Na última parte do estudo, apresentamos a teoria dos regimes de ação e dos modos de justificação de Boltanski e Thévenot. Nesta parte, destacamos a noção de cité, bem como as categorias conceituais formuladas por Boltanski e Thévenot a partir das teorias políticas para caracterização dos regimes de ação. 


\section{O habitus em Bourdieu}

Nas teorias sociológicas do século $\mathrm{XX}$, a abordagem da ação social aparece juntamente com uma análise da estrutura social e uma reflexão sobre a interface entre os atores sociais. Dando ênfase à dimensão simbólica, Bourdieu inovou a sociologia, ao propor a reintrodução dos agentes sociais na análise sociológica, apropriando-se, para tanto, do conceito de estrutura. Todavia, é preciso ressaltar que Bourdieu pretendia se distanciar do estruturalismo por considerá-lo como um enfoque teórico que permanecia atrelado a uma visão macrossociológica da ação social.

Para reintroduzir os agentes sociais na reflexão sobre a ação social, Bourdieu (1996; 2004; 2003) desenvolve o conceito de habitus, tendo como pressuposto a correlação entre as posições sociais, as disposições, as preferências e escolhas dos agentes sociais com estruturas estruturadas. Bourdieu pretende, sobretudo, "eliminar a antinomia da ação e da estrutura", defendendo "uma teoria construtivista [...]" (citado por VANDEBERGHE, 2006, p. 321). Assim, recorre ao conceito de habitus para "reagir contra o estruturalismo e a sua estranha filosofia da ação [...]" (BOURDIEU, 2003, p. 61) que reduzia o agente a um mero suporte de estruturas, pressupondo que o indivíduo não teria uma atitude reflexiva em suas práticas cotidianas, já que a conduta dos agentes sociais seguiria preceitos estabelecidos por instituições sociais previamente estruturadas.

Nas ciências sociais, Durkheim (1999) e Marcel Mauss (2003) referem-se ao conceito de habitus. Em Durkheim (1999), o habitus caracteriza os graus de homogeneidade das sociedades tradicionais e os regimes de internato inspirados no cristianismo e voltados para a educação das crianças. Mauss (2003) empregou o termo habitus no estudo das técnicas corporais, preferindo a versão em latim por esta expressar melhor a concepção aristotélica de hexis.

Bourdieu reformula o conceito de habitus, passando a concebê-lo como um modo de interiorização da exterioridade. $\mathrm{O}$ indivíduo adquire preferências e disposições na medida em que incorpora as estruturas sociais, interiorizando a exterioridade. Daí a visão de que as estruturas seriam estruturantes, já que o agente social as interioriza, adquirindo preferências e formando disposições para agir de uma determinada maneira.

De acordo com Bourdieu (1996), “o habitus [...] é um conhecimento adquirido e também um haver, um capital [...]" que revela a "disposição incorporada" de um agente em ação. "Os habitus são princípios geradores de práticas distintas e distintivas [...]. Eles estabelecem as diferenças entre o que é bom e mau" (BOURDIEU, 1996, p. 22), entre a prática adequada e a inadequada no meio social. A noção de habitus é entendida como um sistema de disposições adquiridas concernentes aos modos através dos quais os agentes constituem categorias de apreciação na medida em que percebem o mundo (BOURDIEU, 2004a).

Entendido como um princípio gerador de práticas distintas no meio social,

o habitus aparece nas preferências e opiniões dos/as agentes sociais. É exatamente o "senso prático" (BOURDIEU, 1996, p. 42), ou seja, uma forma de sabedoria prática, no sentido aristotélico, que direcionaria as ações e escolhas dos/as agentes sociais, 
mediante "um sistema adquirido de preferências, de princípios de visão [...]" incorporados por intermédio "de estruturas objetivas". Ao concebê-lo como um sistema de "disposições adquiridas pela experiência", Bourdieu (2004a, p. 21) acrescenta que as disposições variam de acordo com o lugar e o contexto em que os indivíduos estão inseridos, sendo resultante do senso prático deles.

É preciso enfatizar que, no caso da teoria da ação social de Bourdieu, tratase de agentes e não de sujeitos, tendo em vista que os indivíduos possuem liberdade para agir. Para evidenciar aquilo que chama de "experiência comum do social", Bourdieu (2004a, p. 17) inspirou-se em Husserl, Heidegger e Schütz.

Analisar o "mundo da vida" e o modo de formação da consciência seria a principal tarefa da fenomenologia, para Husserl. Para caracterizar a experiência vivida pelas pessoas na sociedade e o modo como significados e significações são construídos por uma consciência intencional, Husserl (2000) desenvolveu o conceito de "mundo da vida". O mundo da vida é entendido como uma estrutura de conhecimentos comuns compartilhados por membros de uma determinada comunidade ou de um grupo específico.

Conciliando as abordagens de Weber e Husserl, Schütz voltou-se para uma análise do mundo ordinário e das experiências vivenciadas pelas pessoas no cotidiano. A teoria de Schütz (2007) é vista por Bourdieu (2004a, p. 151) como uma proposta que apresenta uma direção inversa se comparada ao objetivismo de Durkheim (1999), na medida em que são evidenciados aspectos da vida cotidiana e "objetos de pensamento" originários do senso comum.

O campo observacional do social scientist, a realidade social, possui um sentido e uma estrutura de pertinência específicos para os seres humanos que nela vivem, agem e pensam. Mediante uma série de construções de senso comum, eles pré-selecionaram e pré-interpretaram esse mundo que apreendem como a realidade de sua vida cotidiana. São esses objetos de pensamento que determinam seu comportamento, motivando-o. (SCHÜTZ, citado por BOURDIEU, 2004a, p. 151).

Os "objetos de pensamento" determinariam o modo de apreensão da realidade, interpretação do mundo, além do comportamento das pessoas. Seriam estes "objetos de pensamento" que motivariam os seres humanos em suas ações. Para apreender a realidade social e as motivações dos indivíduos, o cientista social teria, então, que identificar os "objetos de pensamento".

Com a consciência intencional, o indivíduo constrói um mundo de significações a partir de experiências vividas durante o convívio social. Este é propriamente o campo de observação que o cientista social precisa levar em consideração para analisar a ação social. Os objetos de pensamento são entendidos como forças determinantes que motivariam o comportamento das pessoas na 
O habitus em Bourdieu e a teoria da justificação de Boltanski e Thévenot

sociedade (BOURDIEU, 2004a). Há, portanto, uma referência a fatores determinantes no tocante às ações sociais na concepção do habitus.

\section{Os limites do conceito de habitus}

Ao propor a reintrodução dos agentes na análise da ação social, Bourdieu tentava mostrar que as práticas não poderiam ser reduzidas à execução de regras, contrapondo-se ao estruturalismo de Lévi-Strauss e Althusser que, seguindo a tradição sociológica objetivista, inaugurada por Durkheim (1999), tomava as estruturas sociais como um princípio determinante em relação ao comportamento dos indivíduos. "Os agentes sociais, tanto nas sociedades arcaicas como nas nossas, não são apenas autômatos regulados como relógios" (BOURDIEU, 2004a, p. 21-22), seguindo leis inteligíveis apenas aos cientistas sociais.

Para compreender a ação social seria preciso considerar as preferências e as disposições incorporadas de estruturas estruturantes. Apesar dos questionamentos suscitados em relação ao estruturalismo, Bourdieu enfatiza a relevância das estruturas sociais para a análise do habitus. Interiorizado por intermédio da incorporação de estruturas imanentes do mundo, o habitus revela-se no corpo socializado, entendido como um corpo estruturado. Há, portanto, momentos em que Bourdieu apresenta um posicionamento determinista e objetivista. Principalmente no tocante à perspectiva segundo a qual os objetos de pensamento são determinantes para a ação social e estruturam as práticas.

Mesmo com a tentativa de reintroduzir os agentes sociais na análise da ação social, a abordagem de Bourdieu mantém-se atrelada a um determinismo objetivista. Em Bourdieu há uma proposta de síntese entre as disposições dos agentes e as estruturas objetivas através de uma teoria relacional da ação social. O corpo é socializado na medida em que o indivíduo incorpora as estruturas imanentes do mundo ou do setor no qual está inserido, as quais determinariam o modo de percepção da realidade e direcionariam as ações. Bourdieu relaciona o habitus com a incorporação de estruturas correspondentes à imanência do mundo.

O habitus preenche uma função que, em uma outra filosofia, confiamos à consciência transcendental: é um corpo socializado, um corpo estruturado, um corpo que incorporou as estruturas imanentes de um mundo ou de um setor particular desse mundo, de um campo, e que estrutura tanto a percepção desse mundo como a ação nesse mundo (BOURDIEU, 1996, p. 145).

Caracterizadas pela objetividade, as estruturas estruturantes são definidas como "formas historicamente constituídas, arbitrárias, no sentido de Saussure e de Mauss, cuja gênese social pode ser retraçada" (BOURDIEU, 2001, p. 209). A incorporação praticamente "automática" de estruturas estruturantes desenvolveria "um princípio comum de visão" entre os agentes de um território, uma comunidade ou um grupo. Este princípio comum de visão seria caracterizado por 
"estruturas cognitivas e avaliativas idênticas ou semelhantes [...]" (BOURDIEU, 2001, p. 209).

Conceituando o habitus como um "princípio ativo, irredutível às percepções passivas, de unificação das práticas e das representações [...]" (BOURDIEU, 1996, p. 77), a análise da ação social e do modo de interação entre os indivíduos seria determinada por causas estruturais. Ainda que visto como um princípio ativo, o habitus seria determinado por estruturas estruturantes que unificariam práticas sociais, representações e princípios de visão comuns entre os agentes sociais.

Um movimento dialético de interiorização da exterioridade correspondente a estruturas estruturantes - e de exteriorização da interioridade resulta na formação do habitus. Como ressalta Bourdieu (2002, p. 163),

[...] as estruturas que são constitutivas de um tipo particular de meio ambiente [...] e que podem ser apreendidas empiricamente sob a forma das regularidades associadas a um meio ambiente socialmente estruturado produzem habitus, sistema de disposições duradouras, estruturas estruturadas predispostas a funcionarem como tal, ou seja, enquanto princípio de geração e de estruturação de práticas e de representações que podem ser objectivamente 'reguladas' e 'regulares' sem em nada serem o produto da obediência a regras $[\ldots]$.

Seriam, portanto, as estruturas que produziriam o habitus, isto é, um sistema de disposições que, além de duradouro, estruturaria práticas e representações interiorizadas e exteriorizadas pelos agentes, os quais não teriam plena consciência das operações indispensáveis para ajustar suas motivações com os fins que almejam alcançar em suas ações (BOURDIEU, 2002).

Isto não quer dizer que os indivíduos ajam de modo incoerente. Existiriam condutas razoáveis, para Bourdieu. Admitir a existência de condutas razoáveis não quer dizer que os indivíduos sejam direcionados, em suas atividades cotidianas, pela razão. Quando se refere à conduta, Bourdieu deixa claro que, partindo do pressuposto de que os indivíduos não agiriam de forma incoerente ou insensata, nem por isso se supõe que suas condutas possam ser entendidas como racionais. “O que não significa supor que eles sejam racionais, que têm razão em agir como agem ou mesmo, de maneira mais simples, $[\ldots]$ que suas ações sejam dirigidas $[\ldots]$ ou orientadas por essas razões" (BOURDIEU, 1996, p. 138).

Seguindo a sociologia de Bourdieu, a ação social não é o simples efeito mecânico resultante da coerção de entidades exteriores em relação ao agente. Dotado de um saber prático, o agente social agiria de acordo com a situação. $\mathrm{Na}$ perspectiva de Bourdieu (2004, p. 54), a reflexividade vem do campo na medida em que este é entendido "como espaço de conflitos" ou campo de ação "socialmente construído em que os agentes dotados de diferentes recursos se defrontam para 
conservar ou transformar as relações de força vigentes". Os agentes podem defender a conservação ou a transformação de práticas, todavia, estas são determinadas por objetos de pensamento ou estruturas estruturantes.

Em Bourdieu, a concepção de habitus permanece vinculada à teoria das estruturas na medida em que esta é entendida como uma forma de exterioridade interiorizada. As estruturas se constituem como fatores que determinariam a ação social. Disposições, preferências e princípios de visão adotados pelos agentes sociais seriam, então, determinados por estruturas estruturantes.

Uma análise acerca das disposições dos agentes nos aproximaria do senso prático deles, revelando os modos de percepção e julgamento dos agentes, além dos seus princípios de visão sobre determinada prática. Não obstante, quando nos referimos a atividades da vida cotidiana, percebemos que existem diferentes modos de percepção e julgamento e, por conseguinte, uma variedade relativa de princípios de visão apreendidos pelos agentes sociais e apropriados por eles/as para defender posicionamentos e preferências. Se tomarmos como referência as pesquisas no campo da educação, por exemplo, a "experiência de investigação no domínio das práticas educativas" demonstra que os fatos "não confirmam a tese da representação unificadora das condutas dos indivíduos" (RESENDE, 2003, p. 195).

Para analisar a ação dos indivíduos em sociedade, é imprescindível considerar a pluralidade de interesses e pontos de vista que depende do contexto sociocultural tomado como referência. Uma problemática que aparece na reflexão acerca da ação social é o caráter reflexivo que envolve os/as agentes, suscitando a questão se estes possuem ou não capacidade reflexiva.

É certo que, no curso da ação, os indivíduos se apropriam de princípios apreendidos de realidades sociais "objetivadas e interiorizadas" como destaca Corcuff (2001, p. 27). As realidades sociais remetem-nos "a mundos objetivados: os indivíduos e os grupos se servem de palavras, objetos, regras e instituições, etc., legados pelas gerações anteriores", transformados e recriados por novas gerações. "Estes recursos objetivados, e logo, exteriorizados com relação a eles, agem, por sua vez, como limitações sobre sua ação, oferecendo pontos de apoio para esta ação" (CORCUFF, 2001, p. 27). Deste modo, as realidades sociais objetivadas são entendidas como condições socioculturais que se refletem nas práticas sociais.

Nas atividades do dia a dia, os indivíduos defendem posicionamentos, opiniões, preferências e escolhas, baseando-se em princípios apreendidos na convivência social para justificarem as suas práticas. Neste sentido, na teoria dos modos de justificação desenvolvida por Boltanski e Thévenot, a reflexividade dos indivíduos é levada em consideração para a caracterização da ação social.

\section{Os regimes de ação em Boltanski e Thévenot}

Na obra De la justification, Boltanski e Thévenot (1991) propõem um modelo teórico para investigar o modo como os atores e as atrizes sociais justificam suas ações, destacando disputas, desacordos, controvérsias e acordos em situações da vida cotidiana. No momento em que os indivíduos apresentam críticas e defendem um ponto de vista específico podem surgir controvérsias, disputas e 
Guilherme Paiva de Carvalho Martins

Marcela Carvalho Martins Amaral

desacordos que, ao serem superados, dão origem a acordos em torno de práticas sociais.

$\mathrm{Na}$ investigação das interações em situações de ação são analisados "os modos de justificação ou de crítica" (BOLTANSKI; THÉVENOT, 1991, p. 24) suscitados pelas pessoas na defesa de determinados posicionamentos. Em situações de disputa, os indivíduos são levados a legitimarem suas ações. Os atores e as atrizes apresentam, então, argumentos convincentes para justificar suas práticas ou apresentar críticas, tomando como referência princípios ou realidades objetivadas apreendidas no decorrer da vivência social.

Trazendo um referencial teórico que permite analisar a ação social em situações diversificadas, como no caso de "empresas de setores industriais ou de serviços [...], administrações públicas ou ainda estabelecimentos escolares [...]" (BOLTANSKI; THÉVENOT, 1991, p. 32), a teoria dos regimes de ação dá ênfase às operações críticas e aos modos de justificação.

Enquanto a vertente sociológica durkheimiana evidenciou a noção de coletividade, ressaltando o equilíbrio e a ordem social, a teoria das operações críticas ressalta que seria necessário se deter, doravante, nos "momentos de ruptura da ordem" (BOLSTANSKI; THÉVENOT, 1991, p. 39), isto é, nas crises que surgem quando a ordem estabelecida é suspensa por críticas e disputas que acompanham as atividades cotidianas. A análise dos desacordos e das críticas seria tão relevante quanto o estudo de acordos ou do equilíbrio no tocante à ação social.

Boltanski e Thévenot (1991, p. 53) definem o "imperativo da justificação" como a base que sustenta e coordena a conduta dos indivíduos. Para a teoria da justificação é preciso indagar pelas "consequências do fato de que as pessoas são confrontadas com a necessidade de ter de justificar suas ações [...]" (BOLTANSKI; THÉVENOT, 1991, p. 54).

A teoria dos modos de justificação pressupõe, então, que as pessoas são dotadas de um modelo de competência e de capacidade reflexiva para responder a críticas suscitadas sobre suas práticas, a adoção de técnicas ou de objetos desenvolvidos a partir do conhecimento tecnológico (BOLTANSKI; THÉVENOT, 1991). Para investigar os regimes de crítica e justificação de atores e atrizes sociais é necessário enfatizar o modo como eles/as argumentam para defender um posicionamento específico acerca de uma prática ou da eficácia de determinadas técnicas (THÉVENOT, 2006).

Como mostra Vandenbergue (2006, p. 326), ao referir-se a uma metáfora utilizada por Bernard Lahire, seria possível visualizar a teoria da ação social em Boltanski e Thévenot como uma "passagem da visão top down da macrossociologia bourdieuniana para uma visão bottom up da microssociologia pragmática" que, descendo de pára-quedas na vida social, "mergulharia o observador no meio de ações e interações [...]" entre pessoas em atividades corriqueiras.

Na visão de Corcuff (2001, p. 135), Boltanski buscou "elementos, sobretudo na sociologia de Pierre Bourdieu, com quem trabalhava na época, mas, inscrevendo-os cada vez mais radicalmente em um contexto construtivista". Com o propósito de analisar desacordos, controvérsias e disputas que surgem em um determinado grupo devido à pluralidade de interesses dos indivíduos, Boltanski e Thévenot (1991) conceberam categorias conceituais interessantes para uma 
O habitus em Bourdieu e a teoria da justificação de Boltanski e Thévenot

proposta de reflexão sobre o modo como os atores e as atrizes justificam suas ações.

Com De la justificacion, Luc Boltanski e Laurent Thévenot tomaram como objeto as disputas comuns que ativam $a$ crítica e a justificação das pessoas em espaços públicos, isto é, potencialmente sob o olhar e os pedidos de explicação dos outros membros da coletividade. Eles formularam a hipótese de que, sobre estes debates públicos pesam fortes constrangimentos de legitimidade e de generalidade dos argumentos utilizáveis que levam as pessoas envolvidas a superar a situação particular no interior da qual elas estão engajadas (CORCUFF, 2001, p. 173).

Em situações de desacordo em um dado espaço social, os atores e as atrizes são estimulados/as a apresentarem argumentos convincentes que visam justificar ou legitimar as suas ações. A proposta da teoria da justificação é refletir sobre os desacordos que surgem em situações de interação entre as pessoas com relação ao que se considera como o "bem comum" (BOLTANSKI; THÉVENOT, 1991, p. 92).

Se levarmos em conta o exemplo das sociedades complexas, não há uma visão homogênea acerca do bem comum. Observa-se que esta é mais caracterizada pela pluralidade de posicionamentos, preferências e pontos de vista. Para a sociologia dos regimes de ação é essencial analisar as controvérsias e os desacordos que suscitam críticas por parte de pessoas que interagem com outras em situações do cotidiano.

A noção de bem comum é tomada a partir de clássicos da filosofia política. Boltanski e Thévenot (1991, p. 346) sugerem que "o trabalho filosófico constitui-se como um momento fundamental do processo de generalização $[. .$.$] ", considerando$ a definição do bem comum segundo universos diversificados, ou seja, lógicas de ação diferenciadas chamadas de "cités". É possível compreender a cité "como um modelo analítico que permite identificar os diferentes regimes de justificação que estão na base da crítica", das controvérsias ou dos desacordos "entre os membros de um mesmo espaço social nas sociedades modernas complexas" (RESENDE; DIONÍSIO, 2005, p. 661).

Identificam-se na cité, enquanto modelo analítico, princípios gerais que coordenam as ações das pessoas. Para justificar e legitimar as suas ações, elas referem-se a princípios gerais correspondentes a universos ou mundos. Como sugere Vanderbergue (2006, p. 327), Boltanski e Thévenot pretendem ir de encontro "ao cerne da situação" para analisar as "seqüências de ação e de disputa relativamente curtas" com a intenção de identificar "as operações de justificação". Neste sentido, aproximam-se do pragmatismo norte-americano.

Em cada cité há uma qualificação diferenciada acerca do bem comum. Cités são, portanto, sistemas de referência para os atores e as atrizes sociais que apresentam uma lógica própria e um modo de coordenação da ação. Assim, atores 
e atrizes referem-se a princípios que remetem a um ideal de bem comum para justificarem as suas ações. Para tratar da diversidade das formas de justificação, Boltanski e Thévenot formulam um modelo teórico de tipificação dos regimes de ação, caracterizado por princípios de referência sustentados por atores e atrizes sociais.

Boltanski e Thévenot (1991) relacionam os princípios de legitimação enaltecidos e apresentados pelos indivíduos para justificarem suas ações com categorias conceituais definidas como ordens de grandeza. Estas categorias têm como base o aporte teórico da filosofia política.

As ordens de grandeza são entendidas como princípios de referência adotados por atores e atrizes no curso de suas ações. O uso do termo "grandeur" seria um modo de caracterizar princípios nos quais os indivíduos se apóiam para direcionar suas ações, enaltecendo determinadas práticas. A formulação de tais categorias analíticas constitui uma tentativa de desprender-se "da oposição entre o sujeito livre e o agente preso às práticas sociais coletivas [...]" (THEVENOT, 2006, p. 216).

Os universos ou mundos são entendidos como quadros de referência de acordo com os quais atores e atrizes legitimam suas ações. Cada quadro suscita um tipo específico de forma de coordenação ou orientação da ação que remete a determinadas ordens de grandeza. Desta maneira, existem ordens de grandeza fundamentadas em relações interpessoais cujos princípios têm como referência a tradição (ordem doméstica), na busca pelo reconhecimento dos outros, no renome e no julgamento das pessoas (mundo da opinião), na inspiração e na criatividade do gênio criador e na inovação (mundo da inspiração), nas noções de equidade, vontade geral, interesse da coletividade e nos princípios da cidadania (ordem cívica), nos interesses mercantis baseados na livre concorrência e na obtenção do lucro (ordem mercantil) e na eficácia da produtividade orientada pela racionalidade (ordem industrial).

Correlacionando a "ordem das grandezas" com os clássicos da filosofia política, Boltanski e Thévenot (1991) tomam como referência a Cidade de Deus, de Santo Agostinho, para apresentar o mundo da inspiração, enquanto "o princípio doméstico" é retomado a partir da Política de Bossuet, os símbolos e signos de glória e o mundo da opinião do Leviatã de Hobbes, a noção de vontade geral a partir do Contrato Social de Rousseau, a concepção de riqueza em Adam Smith, baseada no livro Riqueza das nações, e os princípios referentes à eficácia industrial no livro Sistema industrial de Saint-Simon, além da menção à obra Teoria dos sentimentos morais de Adam Smith para caracterizar os princípios prevalecentes no mundo mercantil.

Deste modo, indivíduos que direcionam suas ações de acordo com os princípios da produtividade, da eficácia, da previsibilidade, fundados na técnica e na ciência, por exemplo, levam em consideração princípios que engrandecem o mundo industrial. $\mathrm{O}$ modo de justificação da ação se baseia em tais princípios, enaltecendo a ordem de grandeza industrial como bem comum da cité.

Na abordagem da ação social, Thévenot e Boltanski (1991) reconhecem o "pluralismo" com o qual "as pessoas são confrontadas nas sociedades críticas" (THÉVENOT, 2006, p. 6) na medida em que são provocadas a todo o instante a 
legitimar as suas ações. Com o intuito de justificar práticas, atores e atrizes sociais utilizam capacidades interpretativas e argumentativas na defesa de um posicionamento específico, tentando mostrar a legitimidade de suas ações por meio de argumentos convincentes. Uma pessoa pode utilizar mais de um princípio para justificar sua ação. Os princípios comuns corresponderiam a ordens de grandeza que orientariam a argumentação e a ação de atores e atrizes em situações de interação.

É preciso ressaltar que tais princípios não podem ser entendidos como "sistemas de valores" do modo como foram formulados por Raymond Aron ou Max Weber (BOLTANSKI; THÉVENOT, 1991, p. 166). As ordens de grandeza diferenciam-se "dos sistemas de valores" ou da noção de cultura, compreendida como "valores interiorizados sob a forma de preceitos éticos ou de disposições" que o indivíduo obedeceria "em todas as circunstâncias da vida" (BOLTANSKI; THÉVENOT, 1991, p. 189).

Nas cités identificam-se princípios que correspondem a ordens de grandeza. Tais princípios orientam as ações das pessoas em situações circunstanciais (BOLTANSKI; THÉVENOT, 1991, p. 95). No modelo analítico das cités encontram-se "as noções de grandeza e de bem comum" que reunidas formam um "princípio superior comum" (BOLTANSKI; THÉVENOT, 1991, p. 100). A partir do princípio superior comum é possível identificar desacordos nas situações de interação entre pessoas nos espaços sociais. Este é entendido como um princípio de coordenação da ação que caracteriza um determinado universo (um mundo ou cité) e serve como uma forma de qualificação e enaltecimento de seres ou objetos.

\section{Considerações finais}

Na sociologia contemporânea merecem destaque na abordagem da ação social as teorias de Bourdieu, Bolstanski e Thévenot. Os autores tratados no presente artigo apresentam propostas interessantes para a análise da ação social.

Bourdieu concebe os princípios de visão e o sistema de preferências como habitus incorporados pelos indivíduos a partir de estruturas estruturantes. As estruturas estruturantes incorporadas da exterioridade remeteriam aos princípios de visão e às disposições relacionadas com a concepção de formas avaliativas através das quais os agentes se apropriam para direcionar as suas práticas.

$\mathrm{Na}$ formulação do conceito de habitus, Bourdieu utiliza a noção de hexis em Aristóteles, reformulando-a para caracterizá-la como um saber prático. Bourdieu evidencia a dimensão simbólica de estruturas que são incorporadas pelos agentes sociais, formando disposições duradouras para uma determinada prática social. Apesar de enfatizar aspectos concernentes à subjetividade apreendidos no meio social em uma tentativa de superação do estruturalismo mediante a inclusão dos agentes na análise da ação social, Bourdieu permanece, em alguns momentos, vinculado a uma visão determinista da ação por considerar as estruturas como fatores determinantes das escolhas e preferências dos indivíduos.

Para uma visão mais abrangente acerca da ação social, é preciso reconhecer que na defesa de posicionamentos em relação a práticas, os agentes utilizam uma variedade relativa de pontos de vista. De acordo com a situação, os indivíduos 
podem modificar suas práticas, apropriando-se de novos princípios de visão da realidade, diferentes daqueles que empregavam anteriormente para justificar escolhas ou ações. Por isto, a compreensão da ação social como uma disposição duradoura que tem como pressuposto a incorporação de estruturas estruturantes restringe o campo de análise do cientista social que deixa de considerar a diversidade dos princípios de visão e as mudanças na constituição das subjetividades.

Ao propor uma visão construtivista das práticas, a teoria da justificação e das operações críticas de Boltanski e Thévenot oferece um referencial teórico interessante para a análise da ação social. Em situações de interação, as pessoas se deparam com a necessidade de legitimarem as suas ações. Observando a ação social no cotidiano vivenciado pelas pessoas em situações diversificadas, não é possível sustentar que as estruturas determinam as práticas, transformando-se em disposições mais ou menos duradouras que as pessoas obedeceriam em todas as situações da vida cotidiana. $\mathrm{Na}$ análise da ação social é necessário considerar a pluralidade de interesses de atores e atrizes.

Todavia, ao conceber uma tipologia baseada na filosofia clássica para categorizar os regimes de ação, a abordagem de Boltanski e Thévenot restringe o campo de análise da ação social ao modelo das sociedades ocidentais. Fator que pode dificultar a compreensão da ação social em sociedades caracterizadas pelo multiculturalismo. Na verdade, o propósito da teoria das operações críticas é analisar as sociedades modernas. Apesar desta delimitação ou "limitação" no tocante ao campo de análise, a proposta de indagar pelo modo como os indivíduos justificam as suas ações destaca, sobretudo, a capacidade reflexiva dos indivíduos ao considerá-los não somente como agentes, mas como sujeitos.

\section{Bibliografia}

BOLTANSKI, Luc. A moral da rede? Críticas e justificações nas evoluções recentes do capitalismo. In: Fórum Sociológico. Instituto de Estudos e Divulgação Sociológica, Número 5/6, IIㄹ Série, 2001, pp.13-35.

Le nouvel esprit du capitalisme. Paris: Éditions Gallimard, 1999.

; THÉVENOT, Laurent. De la justification: Les économies de la grandeur. Paris: Éditions Gallimard, 1991.

BOURDIEU, Pierre. A economia das trocas simbólicas. 5. ed. São Paulo: Perspectiva, 2004.

Coisas ditas. Tradução de Cássia R. da Silveira e Denise Moreno Pergorim. São Paulo: Brasiliense, 2004a.

Esboço de uma teoria da prática. Tradução de Miguel Serras Pereira. Oeiras, Portugal: Celta Editora, 2002. 
O habitus em Bourdieu e a teoria da justificação de Boltanski e Thévenot Brasil, 2001.

Meditações pascalinas. Tradução de Sérgio Miceli. Rio de Janeiro: Bertrand O poder simbólico. Tradução de Fernando Tomaz. $6^{\mathbf{a}}$ ed. Rio de Janeiro: Bertrand Brasil, 2003.

Para uma sociologia da ciência. Tradução de Pedro Elói Duarte. Lisboa: Edições 70, 2004b. Razões práticas. São Paulo: Papirus, 1996.

CORCUFF, P. As novas sociologias: construções da realidade social. Trad. Viviane Ribeiro. Bauru, SP: EDUSC, 2001.

HUSSERL, Edmund. Experience et jugement: Recherches en vue d'une genealogie de la logique. Paris: Press Université France, 2000.

LAHIRE, Bernard. Homem plural: os determinantes da ação. Trad. Janime A. Clasen. Petrópolis, RJ: Vozes, 2002.

MAUSS, Marcel. Sociologia e antropologia. Tradução de Paulo Neves. São Paulo: Cosac Naify, 2003.

RESENDE, José Manuel. O Engrandecimento de uma Profissão: Os Professores do Ensino Secundário Público no Estado Novo. Lisboa: FCT/FCG, 2003.

RESENDE, José Manuel; DIONÍSIO, Bruno Miguel. Escola pública como arena política e ambivalências da socialização política escolar. In: Análise Social, vol. XL (176), 2005, pp. 661-680.

SCHÜTZ, Alfred. Essais sur le monde ordinaire. Paris: Le Félin Proche, 2007.

THÉVENOT, Laurent. L'action au pluriel: sociologie des regimes d'engagement. Paris: Éditions La Découverte, 2006.

VANDENBERGUE, Frédéric. Construção e crítica na nova sociologia francesa. In: Sociedade e Estado, Departamento de Sociologia da Universidade de Brasília, Brasília, v. 21, n.2, 2006, pp. 315-366. 